PRISCILA KÜHL ZOGHBI

\title{
Poder de Controle E Direito à Privacidade do Trabalhador nas \\ REDES SOCIAIS
}

Dissertação de Mestrado

Orientador: Professor Associado Dr. Otavio Pinto e Silva

UNIVERSIDADE DE SÃO PAULO

FACULDADE DE DIREITO

SÃo PAULO - SP

2020 
PRISCILA KÜHL ZOGHBI

Poder de Controle e Direito À Privacidade do Trabalhador nas

REDES SOCIAIS

Dissertação apresentada à Banca Examinadora do Programa de Pós-Graduação em Direito, da Faculdade de Direito da Úniversidade de São Paulo, como exigência parcial para obtenção do título de Mestre em Direito, na área de concentração Direito do Trabalho e Seguridade Social, sob a orientação do Professor Associado Dr. Otavio Pinto e Silva

UNIVERSIDADE DE SÃO PAULO

\section{FACULDADE DE DIREITO}

SÃo PAULO - SP

2020 
Catalogação da Publicação

Serviço de Biblioteca e Documentação

Faculdade de Direito da Universidade de São Paulo

Zoghbi, Priscila Kuhl

PODER DE CONTROLE E DIREITO À PRIVACIDADE DO

TRABALHADOR NAS REDES SOCIAIS ; Priscila Kuhl Zoghbi

- orientador Otavio Pinto e Silva -- São Paulo, 2020.

140

Dissertação (Mestrado - Programa de Pós-Graduação em Direito do Trabalho e Seguridade Social) - Faculdade de Direito, Universidade de São Paulo, 2020.

1. Direito. 2. Direito do Trabalho. I. Silva, Otavio Pinto e, orient. II. Título. 


\section{PRISCILA KÜHL ZOGHBI}

Dissertação apresentada à Banca Examinadora do Programa de Pós-Graduação em Direito, da Faculdade de Direito da Universidade de São Paulo, como exigência parcial para obtenção do título de Mestre em Direito do Trabalho, sob orientação do Professor Associado Otavio Pinto e Silva

São Paulo, de 2020.

\section{BANCA EXAMINADORA}

Prof. Dr.

Instituição:

Assinatura:

Prof. Dr.

Instituição:

Assinatura:

Prof. Dr.

Instituição:

Assinatura: 
À minha primeira professora, Olympia Kuhl (In memoriam). 


\section{AGRADECIMENTOS}

Acredito ser essa, apesar de singela, uma das partes fundamentais da dissertação, pois, se ela se conclui, é somente pelo apoio que recebi ao longo de todo seu desenvolvimento.

À Faculdade de Direito da Universidade de São Paulo, que me acolheu há mais de 10 anos como aluna e me formou como acadêmica, cidadã, mulher e feminista. Lugar que carinhosamente também chamo de casa.

Ao meu orientador, professor associado doutor Otavio Pinto e Silva, pelos ensinamentos, orientações e principalmente pela inquestionável paciência ao longo dos anos. Obrigada pelo voto de confiança em aceitar me orientar.

A minha mãe, Keila Oliveira Zoghbi, que tornou tudo possível com o simples ato de acreditar, costurando suas asas em mim. Certamente minha gratidão não cabe em palavras. Obrigada pelo carinho e incentivo incondicionais. Você é minha árvore generosa.

Ao meu pai, Salomão Zoghbi Neto, por quem minha imensa admiração sempre serviu de estímulo.

Ao meu companheiro, Vinicius Costa Meneses Nunes, por não ter largado minha mão mesmo em momentos difíceis.

A todos os meus amigos e familiares que, cada um à sua forma, me auxiliaram nessa trajetória. 
"A privacidade, disse, era uma coisa muito valiosa. Todo mundo queria ter um lugar em que pudesse estar a sós de vez em quando. E quando alguém encontrava um lugar assim, não era senão um gesto da mais trivial cordialidade que aqueles que soubessem do fato guardassem a informação para si mesmos."

George Orwell - 1984 . 


\section{RESUMO}

A pesquisa tem como escopo abordar, dentro do Direito do Trabalho, as consequências de um inquestionável fenômeno da atualidade: o surgimento e a massificação de novas tecnologias, permitindo, cada vez mais, um intenso fluxo de informações jamais vivenciado nessa escala pela humanidade. Conscientes do novo cenário em que estamos vivendo, a pesquisa analisou um antigo dilema do Direito do Trabalho: o poder diretivo do empregador versus direitos da personalidade, em especial o direito à privacidade do empregado no contrato laboral, porém sob um novo enfoque: as redes sociais virtuais. Para tanto, o estudo do conceito, terminologia, natureza jurídica, dimensões, limitações, sem esquecer as trajetórias históricas do instituto do poder diretivo - com foco no poder de controle - e dos direitos da personalidade e, em específico, do direito à privacidade, apresenta-se fundamental para a construção de uma base teórica que permita reflexões e possíveis soluções sobre o tema. Trata-se, sem dúvida, de um assunto extremamente delicado, pois não apenas envolve a possibilidade de colisão entre direitos fundamentais e seus reflexos em garantias sociais já consagradas, como também resvala no valor maior em que se baseia o próprio estado democrático brasileiro: a dignidade da pessoa humana. A busca pela harmonização entre os referidos direitos revela-se, portanto, urgente e essencial nesse momento da modernidade. Para tanto, não só se utilizaram textos doutrinários, como também se analisaram as respostas dadas pelos tribunais, tanto no âmbito nacional quanto no internacional.

Palavras-chave: Poder diretivo; Poder de controle; Direitos da personalidade; Privacidade; Redes sociais. 


\begin{abstract}
This research aims to approach, inside the Labor Law system, the consequences of a nowadays unquestionable phenomenon: new technologies emerging and its popularization, allowing a massive information flow never seen before in such scale by humankind. Conscious of the new scenario we're living in, the research analyzed an old labor law dilemma: the employer directive power versus personality rights, specially what concerns the employee rights to privacy in a labor contract however through a new angle: the virtual social networks. Thereby, the concept, terminology, juridical nature, dimensions, limitations, not to mention historical trail, of directive power institutes study - targeting the control power - of personality rights and, notably, of the rights to privacy, present themselves fundamental to a solid theoretical basis building that allows us to reflect about possible solutions to the proposed argument. The subject is, undoubtedly, extremely sensitive, once it commits not only the possibility of collision of fundamental rights and their reverberations in consecrated social guaranties, as well as it brushes with a greater value in which Brazilian democratic state itself is amalgamated upon: the human being dignity. The harmonization quest between the rights above reveals itself, thus, urgent and essential at this modern times. For this purpose, not only doctrinaire texts were utilized and analyzed but also Courts decisions, including national and international ones.
\end{abstract}

Keywords: Directive Power; Control Power; Personality Rights; Privacy; Social Networks. 


\section{RIASSUNTO}

Lo scopo della ricerca è quello di affrontare, all'interno del Diritto del Lavoro, le conseguenze di un indiscutibile fenomeno attuale: l'emergere e la massificazione di nuove tecnologie, consentendo sempre più un intenso flusso di informazioni mai sperimentato dall'umanità su questa scala. Consapevoli del nuovo scenario in cui viviamo, la ricerca ha analizzato un vecchio dilemma del diritto del lavoro: il potere di direttiva del datore di lavoro versus i diritti della personalità in particolare il diritto alla privacy del dipendente nel contratto di lavoro, ma sotto una nuova prospettiva: le social network virtuali. A tal fine, lo studio del concetto, la terminologia, la natura giuridica, le dimensioni, i limiti, senza dimenticare le traiettorie storiche, gli istituti del potere direttivo - concentrandosi sul potere di controllo - i diritti della personalità e, in particolare, il diritto alla privacy, si presentano fondamentali per la costruzione di una base teorica che ci permetta riflessioni e possibili soluzioni sul tema. Si tratta senza dubbio di una questione estremamente delicata, poiché coinvolge non solo la possibilità di uno scontro tra i diritti fondamentali e i loro riflessi sulle garanzie sociali già stabilite, ma anche scivola nel maggior valore su cui si basa lo stesso Stato democratico brasiliano: la dignità della persona umana. La ricerca dell'armonizzazione tra questi diritti è, quindi, urgente ed essenziale in questo momento di modernità. A tal fine sono stati utilizzati non solo testi dottrinali, ma sono state anche analizzate le risposte date dalle Corti, sia a livello nazionale che internazionale.

Parole Chiavi: Potere Direttivo; Potere di Controllo; Diritti della Personalità; Privacy; Social Media. 


\section{RESUME}

Le but de la recherche est d'aborder, au sein du droit du travail, les conséquences d'un phénomène incontestable d'aujourd'hui : l'émergence et la massification de nouvelles technologies, permettant de plus en plus un flux intense d'informations jamais connu à cette échelle par l'humanité. Prenant en compte le nouveau scénario dans lequel nous vivons, la recherche a analysé un vieux dilemme du Droit du Travail: le pouvoir directif de l'employeur versus les droits de la personnalité, en particulier le droit à la vie privée du salarié dans le contrat de travail, mais sous un nouvel axe : les réseaux sociaux virtuels. Ainsi, l'étude du concept, de la terminologie, de la nature juridique, des dimensions, des limites, sans oublier les trajectoires historiques, les instituts du pouvoir directif - focalisés sur le pouvoir de contrôle - des droits de la personnalité et, plus précisément, du droit à la vie privée sont fondamentale pour la construction d'une base théorique qui nous permet de réfléchir pour trouver des solutions possibles sur le thème. Il s'agit sans aucun doute d'une question extrêmement délicate, car elle implique non seulement la possibilité d'une collision entre les droits fondamentaux et leurs réflexes dans des garanties sociales déjà établies, mais aussi la plus grande valeur sur laquelle l'État démocratique brésilien lui-même est fondé : la dignité de la personne humaine. La recherche d'une harmonisation entre ces droits est donc urgente et essentielle en ce moment de l'actualité. À cette fin, non seulement des textes doctrinaux ont été utilisés, mais les réponses données par les tribunaux ont également été analysées, tant au niveau national qu'international.

Mots-clés : Pouvoir de Direction ; Pouvoir de contrôle ; Droits de la personnalité ; Privacité ; Réseaux sociaux. 


\section{SUMÁRIO}

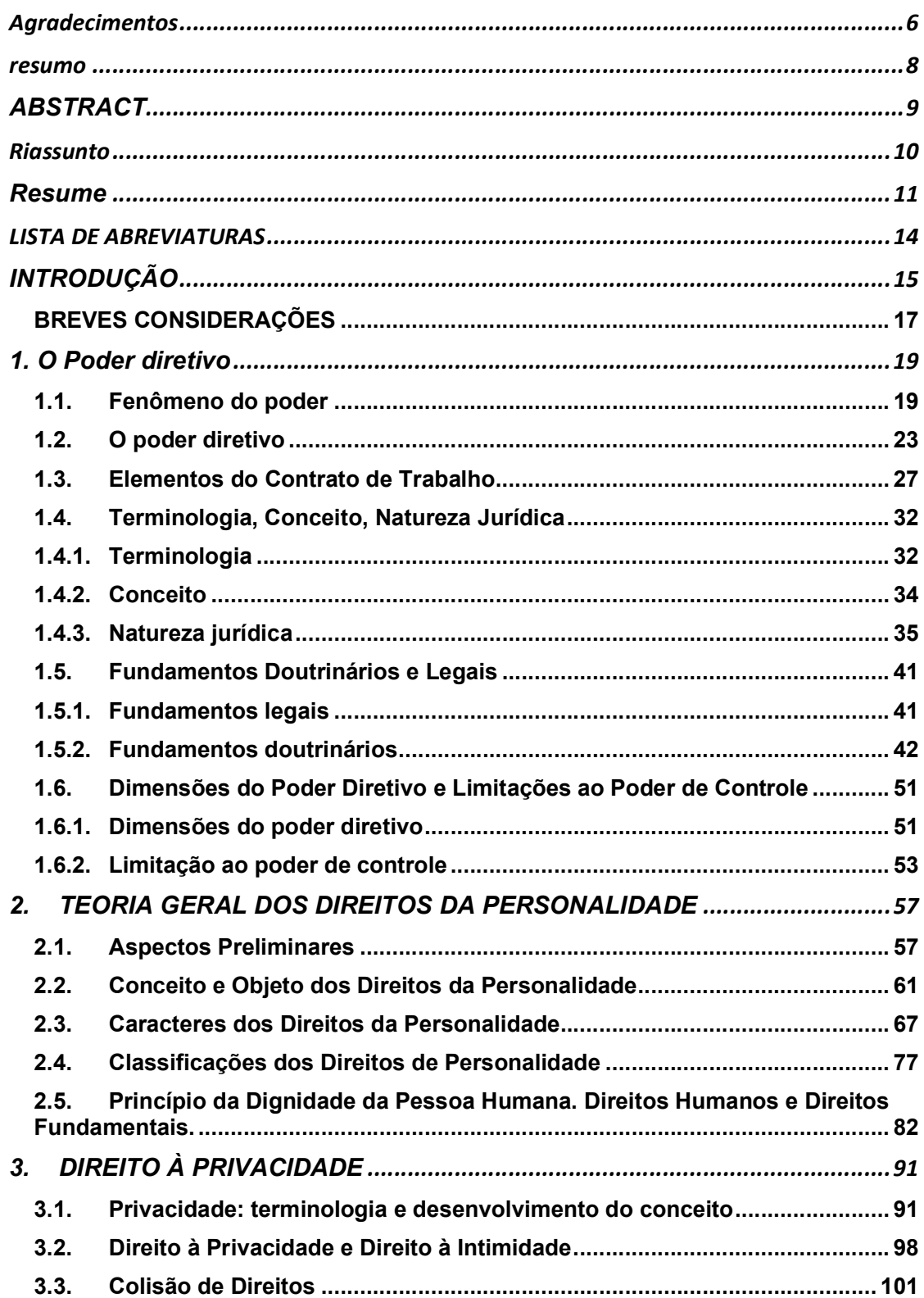




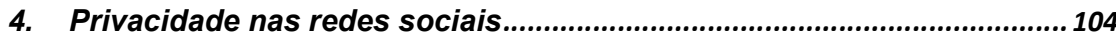

4.1. Breves Considerações .......................................................................... 104

4.2. Novas Tecnologias e o Direito do Trabalho......................................... 107

4.3. Análise de Redes Sociais .................................................................111

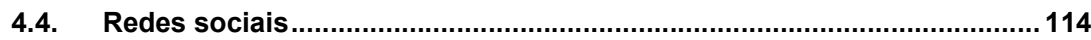

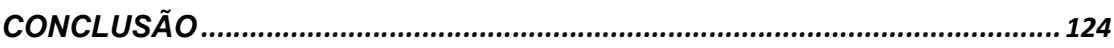

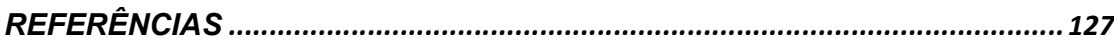

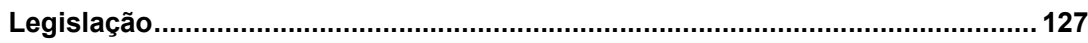

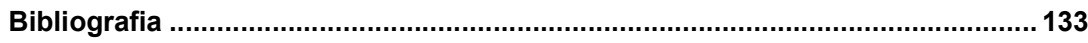




\section{LISTA DE ABREVIATURAS}

$\begin{array}{ll}\text { Art. } & \text { Artigo } \\ \text { CEDH } & \begin{array}{l}\text { Cour Européenne des Droits de l'homme [=Corte Européia de } \\ \text { Direitos do Homem] }\end{array} \\ \text { CC } & \text { Código Civil } \\ \text { CF } & \text { Constituição da República Federativa do Brasil } \\ \text { CP } & \text { Código Penal } \\ \text { CT } & \text { Código do Trabalho português } \\ \text { EUA } & \text { Estados Unidos da América } \\ \text { CLT } & \text { Consolidação das Leis do Trabalho } \\ \text { DL } & \text { Decreto- Lei } \\ \text { OIT } & \begin{array}{l}\text { Organization Internacional du Travail [=Organização } \\ \text { Internacional do Trabalho] }\end{array} \\ \text { ONU } & \text { Organização das Nações Unidas } \\ \text { PL } & \text { Projeto de Lei } \\ \text { TST } & \text { Tribunal Superior do Trabalho } \\ \text { TRT } & \text { Tribunal Regional do Trabalho } \\ \text { UE } & \text { União Europeia }\end{array}$




\section{INTRODUÇÃO}

Ao falar em avanço tecnológico e privacidade, não é incomum a menção a 1984, livro escrito por George Orwell. No romance, o mundo fragmenta-se em três grandes blocos (Oceânia, Eurásia e Lestásia), todos comandados por um regime totalitário, com diferenças pouco notórias se comparados ao que apresentam em comum. Na Oceânia, o "Partido", assim denominado o grupo dominante, é liderado pelo "Grande Irmão" (Big Brother), o qual controla, de várias formas, a vida dos "companheiros". Um dos exemplos mais famosos desse controle consiste na teletela a ser uma tela ligada de forma contínua, que não apenas serve como instrumento de divulgação de notícias, mas também possui como principal função a percepção e absorção de conversas, barulhos e todos os atos em frente à dela praticados. Não seria fortuito que as teletelas fossem instaladas em diversos lugares estrategicamente pensados, inclusive dentro das casas. O ponto focal do romance consiste na sensação - e realidade - de vigilância ininterrupta. ${ }^{1}$

Apesar de escrito no século passado, é possível deduzir que, em alguns aspectos, o romance utópico possui pontos de similitude com o que ocorre nos dias de hoje. Um deles é, sem dúvida, a corrosão da privacidade. No entanto, a realidade difere do livro, ao constatar que o aviltamento da privacidade é muitas vezes realizado - às vezes desejado - pelos próprios indivíduos. Ademais, ante uma nova forma de governo, democrático e fomentador, ao invés de autoritário, os principais perigos à privacidade resultam de relações privadas, entre as quais encontra relevo a relação de emprego.

A priori, a vigilância, assim entendida como uma das expressões do poder, é realizada dentro do seio do direito privado. Nesse sentido, há cenários em que o "Grande Irmão" atual pode traduzir-se nas empresas privadas. Faz-se indispensável a determinação de restrições a esse poder - de fiscalização com o intuito de resguardar a privacidade das partes componentes da relação empregatícia, em especial, o empregado. Isso porque a divisão de poder dentro dessa forma de relação jurídica está longe de ocorrer de forma equânime.

1 ORWELL, George. 1984. São Paulo: Companhia das Letras, 2009. 
Utilizando-se da máxima de Montesquieu, o detentor do poder tende a dele abusar. ${ }^{2}$ Sendo o empregado o elo mais fraco, não só é possível como provável que seus direitos sejam lesionados. Em vista disso, esta pesquisa pretende analisar a questão do controle fiscalizatório do empregador, incluindo seus limites, a fim de que esse não sirva de instrumento que permita lesionar direitos fundamentais do empregado. Tendo em vista a complexidade do tema proposto, buscamos analisar a vexata quaestio no âmbito das redes sociais virtuais.

Por isso, o primeiro capítulo é destinado ao estudo do fenômeno do poder, principalmente com base na análise do poder diretivo, incluindo os principais conceitos propostos pela doutrina, a natureza jurídica do instituto, suas dimensões e limites. Dentro do poder diretivo, damos maior relevo ao poder de controle, pois é em seu âmbito que a fiscalização ocorre.

O direito à privacidade não se encontra sozinho no que diz respeito aos direitos indispensáveis ao homem: situa-se na esfera dos direitos da personalidade. Isso posto, é necessário para o entendimento do direito à privacidade como categoria o exame de seu gênero. Para tanto, no segundo capítulo, tratamos dos direitos da personalidade abrangendo sua perspectiva histórica, definição, natureza jurídica e tipologia, no qual abordamos o princípio norteador - e limitador - de qualquer direito dentro do ordenamento jurídico: o princípio da dignidade humana e seus desdobramentos em direitos humanos, fundamentais e de personalidade.

Seria esperado que, em um cenário de ofensa à determinado direito por seus detentores, fosse mais ferrenhamente defendido. Mas, no que concerne ao direito à privacidade, ocorre justamente o contrário. Ante o surgimento de novas e mais eficientes ferramentas fiscalizatórias, por isso ameaçadoras à privacidade, grande parte dos indivíduos opta por dilapidá-lo de forma voluntária. Com uma breve análise da privacidade ao longo dos últimos dois séculos, percebe-se uma verdadeira inversão ao que remete à defesa do instituto.

O terceiro capítulo, portanto, é dedicado ao estudo desse direito da personalidade específico, o direito à privacidade, além de seu histórico, alteração do seu valor dentro da sociedade e a diferenciação entre ele e o direito à intimidade.

${ }^{2}$ MONTESQUIEU, Charles de Secondat, Baron de. Do espirito das Leis. São Paulo: Martin Claret, 2014. 
Fornecido o aparato teórico-conceitual necessário, partimos então para o último capítulo, no qual é feita a análise da relação entre privacidade e uma das inovações tecnológicas de mais forte impacto na sociedade: as redes sociais virtuais propiciadas pela massificação da Internet e sua interferência nas relações de emprego. Iniciamos examinando o próprio conceito de redes e sua aplicação no âmbito sociovirtual.

Nesse capítulo estudamos também como os tribunais, no âmbito tanto nacional quanto internacional, estão interpretando e elaborando soluções para os casos relacionados às demandas decorrentes de novas tecnologias. Iniciamos com o exame de instrumentos tecnológicos que possuem maior consolidação na Jurisprudência trabalhista como fiscalização por meio de videocâmeras de segurança e correio eletrônico. Em sequência, debruçamo-nos aos julgados referentes às redes sociais virtuais incluindo-se aqui as diversas formas de expressão, tais como "likes", "curtidas", entre outras.

Por fim, apresentamos as conclusões.

\section{BREVES CONSIDERAÇÕES}

Levando-se em conta que as implicações do poder dentro da sociedade e, portanto, do direito do trabalho são amplas e complexas, nesta pesquisa o fenômeno do poder foi analisado no âmbito da relação de emprego, assim entendida como espécie do gênero relação de trabalho, caracterizada pelo elemento da subordinação. ${ }^{3}$

Ademais, esta pesquisa não tratou dos casos especiais, tais como: o empregado doméstico, regulado pela Lei $n^{\circ} 5.859 / 72,{ }^{4}$ estagiário, trabalhador eventual, trabalhador avulso, trabalhador rural, regulamentado pela Lei $n^{\circ} 5.889 / 73^{5}$ e pelo Decreto $\mathrm{n}^{\circ} 73.626 / 74^{6}$ entre outros.

3 RUSSOMANO, Mozart Victor. Curso de Direito do Trabalho. 9. ed. Curitiba: Juruá, 2016. p. 69.

${ }^{4}$ Lei $n^{\circ} 5.859$, de 11 de dezembro de 1972. Dispõe sobre a profissão de empregado doméstico e dá outras providências. Disponível em: https://www2.camara.leg.br/legin/fed/lei/1970-1979/lei-585911-dezembro-1972-358025-publicacaooriginal-1-pl.html. Acesso em: 29 set. 2020.

${ }^{5}$ Lei $n^{\circ} 5.889$, de 8 de junho de 1973. Estatui normas reguladoras do trabalho rural. Disponível em: http://www.planalto.gov.br/ccivil 03/leis/15889.htm. Acesso em: 29 set. 2020.

${ }^{6}$ Decreto $n^{\circ} 73.626$, de 12 de fevereiro de 1974. Aprova Regulamento da Lei $n^{\circ} 5.889$, de 8 de junho de 1973. Disponível em: http://www.planalto.gov.br/ccivil 03/decreto/1970-1979/D73626.htm. Acesso em: 29 set. 2020. 
Outro ponto fundamental é que este estudo tem por foco as redes sociais virtuais, que por nós serão chamadas apenas de "redes sociais". 


\section{CONCLUSÃO}

Como visto, o fenômeno tecnológico não deixou incólume a tradicional disputa entre o poder do empregador lato sensu e os direitos dos empregados, sejam como tais, sejam como apenas cidadãos.

O poder, de acordo com os ditames foucaultianos, não é algo estático. No âmbito laboral, este se altera mediante uma série de critérios, desde o tempo e a cultura até o regime estatal a que a empresa está submetida. Percebemos que o fenômeno do poder foi modificado pela inserção de novas e mais acessíveis tecnologias, reorganizando sua distribuição e fortalecendo, em vários sentidos, a vigilância ou fiscalização, o que tornou possível maior controle da vida privada dos indivíduos. No entanto, conforme já explorado, o fenômeno de maior fiscalização não ocorreu apenas dentro da esfera do direito do trabalho, consistindo, na realidade, em uma verdadeira tendência global.

Ademais, de acordo com Montesquieu: "é uma experiência eterna a de que todo homem que tem poder é evado a abusar dele; ele vai em frente até encontrar limites. (...) Para que não se possa abusar do poder, é preciso que, pela disposição das coisas, o poder tenha o poder". ${ }^{422}$ Transportando a máxima para a esfera laboral o detentor do poder diretivo muito provavelmente será levado a cometer abusos. Dito de outra forma, é inconteste a preocupação de que as novas tecnologias se tornem instrumento facilitador para o aumento da assimetria já existente entre as partes no âmbito laboral.

Percebemos que são vários os limites previstos ao poder diretivo do empregador. Esse, como vimos, não trata de uma forma de sujeição do empregado ao empregador. Em síntese, o poder conferido ao empregador tem como função facilitar e propiciar o atingimento dos objetivos almejados pela empresa, e não a satisfação de interesses egoísticos do empregador. Ademais, o exercício do poder diretivo deve estar em conformidade com os princípios constitucionais referentes à função social do contrato.

Entre os limites frequentemente aludidos ao poder diretivo, citam-se as normas previstas na Consolidação das Leis de Trabalho, nos acordos e/ ou

${ }^{422}$ MONTESQUIEU, Do espírito... op. cit., p. 229. 
convenções coletivas (legislação), o próprio contrato de trabalho e os direitos de personalidade do empregado.

No entanto, não se deve perder de vista que todos os limites supracitados possuem uma base fundamental, supralegal, em comum: o princípio da proteção da dignidade da pessoa humana. Isso, ao aceitar ser parte de um contrato laboral, tornando-se, portanto, empregado, este não se "despe" de forma alguma dos direitos fundamentais garantidos a qualquer pessoa. $O$ trabalhador é, frise-se, antes de tudo, um cidadão.

Nesse sentido, o reconhecimento de novos direitos de personalidade, ou de novas formas de expressão de direitos já conhecidos, deve estar alinhado com as mudanças sociopolíticas enfrentadas pela sociedade.

Nesse contexto, acreditamos ser um indiscutível avanço a positivação de direitos até então não reconhecidos aos cidadãos, da mesma forma que a previsão de limites mais específicos ao poder diretivo. Entretanto, deve-se estar atento para que o texto legal não seja um instrumento que obstaculize ou impeça a proteção de direitos fundamentais. Caso contrário, tratar-se-ia, na realidade, de lesão aos princípios basilares que fundam o próprio Estado Democrático de Direito.

Indiscutivelmente um dos fenômenos que mais geraram impactos na sociedade nos últimos anos foi a evolução rápida de mecanismos tecnológicos que facilitam a interação entre seres humanos, como as redes sociais. $O$ impacto desse fenômeno nas relações de emprego é contundente e suas margens restam ainda indefinidas. Contudo, percebemos que as redes sociais e a internet como um todo alteraram a própria morfologia do Direito do Trabalho.

Diante disso, observamos que o legislador, em razão do rápido crescimento desse meio de comunicação e de seus reflexos na sociedade, produziu a Lei $n^{\circ}$ 12.965, de 23 de abril de 2014, comumente conhecida como Marco Civil da Internet, que estabelece princípios, garantias e deveres para o uso da Internet no Brasil e, de forma mais recente, a Lei Geral de Proteção de Dados (Lei n 13.709, de 14 de agosto de 2018).

Desse modo, apesar de termos percebido uma mudança de perspectiva normativa, é essencial que, de forma concomitante, se analisem os remédios legais e os critérios utilizados pelos tribunais para o julgamento das novas demandas 
surgidas em detrimento da inserção das inovações tecnológicas no seio da sociedade moderna.

$\mathrm{Na}$ realidade, deve-se reconhecer que o fenômeno tecnológico é amplo demais para apenas analisá-lo sob a ótica jurídica. Torna-se fundamental para o estudo das consequências do avanço tecnológico e seus reflexos nas relações jurídicas e, em especial, nas relações de trabalho, a associação com outras áreas do conhecimento científico, como a psicologia, a ciência de dados, entre outras.

Tudo isso considerado é possível deduzir que o avanço tecnológico e, por consequência, a proliferação de instrumentos fiscalizatórios tratam de um fenômeno irrefreável que ameaça de forma cristalina, a classe dos direitos fundamentais, com especial destaque ao direito à privacidade, o qual, por sua vez, vem sendo alvo da própria transformação.

Neste estudo, propusemos que a inserção de tecnologias na sociedade trouxe consequências aparentemente díspares: modernização e massificação de instrumentos fiscalizatórios aliados à dilapidação do direito à privacidade. $\mathrm{O}$ assunto ganha ainda mais importância quando analisado dentro de uma relação em que as partes se encontram em patamares distintos, prevalecendo um dos atores: o empregador.

Não é por outra razão, portanto, que o ordenamento jurídico laboral tem por objetivo e dever proteger o elo mais fraco da relação, o empregado. Nesse sentido, é fundamental o empenho do operador de direito em proteger os direitos do empregado.

Em contrapartida, o operador do direito deve ter em vista as mudanças sociais ocorridas ou ainda em movimento, como a massificação da utilização voluntária por empregados de ferramentas que transformam informações privadas ou íntimas em públicas. 


\section{REFERÊNCIAS}

\section{LEGISLAÇÃO}

ALEMANHA. [Constituição (1911)]. Die Verfassung des Deutschen Reichs(„Weimarer Reichsverfassung“) vom 11. August 1919. Disponível em: https://www.jura.uni-

wuerzburg.de/fileadmin/02160100/Elektronische_Texte/Verfassungstexte/Die_Wei marer_Reichsverfassung_2017ge.pdf. Acesso em: 01 out. 2020.

Bürgerliches Gesetzbuch. Disponível em: http://www.gesetze-iminternet.de/bgb/ Acesso em: 01 out. 2020.

Grundgesetz Für Die Bundesrepublik Deutschland. Disponível em: HTTPS://WWW.GESETZE-IM-INTERNET.DE/GG/BJNR000010949.HTML.

Acesso em: 01 out. 2020

BRASIL. [Constituição (1891)]. Constituição da República dos Estados Unidos do Brasil.

Brasil.

[Constituição (1934)]. Constituição da República dos Estados Unidos do

[Constituição (1937)]. Constituição dos Estados Unidos do Brasil.

[Constituição (1946)]. Constituição dos Estados Unidos do Brasil.

[Constituição (1967)] Constituição da República Federativa do Brasil

[Constituição (1988)]. Constituição da República Federativa do Brasil.

Decreto $n^{\circ} 4.657$, de 4 de setembro de 1942. Lei de Introdução às normas do Direito Brasileiro. Diário Oficial da União, Brasília, DF, 9 set. 1942, Seção 1, p. 13635.

Decreto-Lei $n^{\circ} 5.452$, de $1^{\circ}$ de maio de 1943 . Consolidação das Leis do Trabalho (CLT). Diário Oficial da União, Brasília, DF, 09 ago. 1943, Seção 1, p. 11.937. 
Lei $n^{\circ} 5.859$, de 11 de dezembro de 1972. Dispõe sobre a profissão de empregado doméstico e dá outras providências. Diário Oficial da União, Brasília, DF, 12 dez. 1972, Seção 1, p. 11065.

Lei $n^{\circ} 5.889$, de 8 de junho de 1973. Estatui normas reguladoras do trabalho rural. Diário Oficial da União, Brasília, DF, 12 jun. 1973, Seção 1, p. 5585.

Decreto $\mathrm{n}^{\circ}$ 73.626, de 12 de fevereiro de 1974. Aprova Regulamento da Lei $n^{\circ} 5.889$, de 8 de junho de 1973. Diário Oficial da União, Brasília, DF, 13 fev. 1974 , Seção 1, p. 1642.

Lei $n^{\circ} 8.231$, de 24 de julho de 1991. Dispõe sobre os Planos de Benefícios da Previdência Social e dá outras providências. Diário Oficial da União, Brasília, DF, 25 jul. 1991, Seção 1, p. 14.809.

Lei $n^{\circ}$ 9.296, de 24 de julho de 1996. Regula o inciso XII, parte final, do $\overline{\text { Artigo }}^{\circ}$ da Constituição Federal. Diário Oficial da União, Brasília, DF, 25 jul. 1996, Seção 1, p. 13.757.

Lei n 10.406, de 10 de janeiro de 2002. Institui o Código Civil. Diário Oficial da União, Brasília, DF, 11 jan. 2002, Seção 1, p. 1.

Lei $n^{\circ} 13.271$, de 15 de abril de 2016. Dispõe sobre a proibição de revista íntima de funcionárias nos locais de trabalho e trata da revista íntima em ambientes prisionais. Diário Oficial da União, Brasília, DF, 18 abr. 2016, p. 1, col. 1.

Lei $n^{\circ}$ 13.869, de 05 de setembro de 2019. Lei de Abuso de Autoridade. Diário Oficial da União, Brasília, DF, 05 set. 2019, Seção 1, Edição Extra. p. 1.

ESPAÑA. [Constituição (1978)] Constitución Española. Disponível em: https://www.boe.es/buscar/act.php?id=BOE-A-1978-31229. Acesso em: 11 set. 2020.

Ley orgánica 1/1982 de 5 de mayo de 1982. De protección civil del derecho al honor, a la intimidad personal y familiar y a la propia imagen. Boletín Oficial del Estado, Madrid, 14 mayo 1982, n. 115, p. 12546-12548.

FRANCE. Code Civil. Version consolidée au 1 septembre 2020. Disponível em: https://www.legifrance.gouv.fr/affichCode.do?cidTexte=LEGITEXT000006070721, Acesso em: 11 set. 2020 
INTERNATIONAL LABOUR ORGANIZATION. Constitution. Disponível em: https://www.ilo.org/dyn/normlex/en/f?p=1000:62:0::NO::P62_LIST_ENTRIE_ID,P6 2_LANG_CODE:2453907,fr:NO\#declaration. Acesso: 02 out. 2020.

ITALIA. [Constituição (1947)]. Constituzione dela Repubblica Italiana. Disponível em: https://www.senato.it/documenti/repository/istituzione/costituzione.pdf, Acesso em: 11 set. 2020

CORTE CONSTITUZIONALE. Sentenza n. 38. DJ: 5/4/1973. Disponível em: http://www.giurcost.org/decisioni/1973/0038s-73.html. Acesso em: 11 set. 2020.

CORTE DI CASSAZIONE CIVILE: 990. DJ: 20/4/1963. Disponível em: http://www.jus.unitn.it/users/pascuzzi/varie/sem-inf99/Cass 1963.htm. Acesso em: 19 set. 2020 .

Codice $\quad 2020.2$ Divile em: https://www.altalex.com/documents/codici-altalex/2015/01/02/codice-civile Acesso em: 19 set. 2020.

$\begin{array}{lll}\text { Disponível } & \text { em: } & \text { https://www.altalex.com/documents/codici- } \\ \text { altalex/2014/10/30/statuto-dei-lavoratori. Acesso em: } 19 \text { set. } 2020 .\end{array}$

Statuto dei lavoratori 2020. II testo aggiornato della legge 300/1970.

MÉXICO. Ley Federal del Trabajo. Disponível em: http://www.diputados.gob.mx/LeyesBiblio/pdf/125 020719.pdf. Acesso em: 08 de out. 2020 .

PORTUGAL. [Constituição (1933)]. Constituição Portuguesa de 1933. Disponível em : http://cadeiras.iscte-iul.pt/SDir/SDir Ik Doc ConstP 1933.pdf. Acesso em: 01 out. 2020.

Disponíve

[Constituição (1973)]. Constituição da República Portuguesa de 1976. aspx. Acesso em: 01 out. 2020.

Lei $n^{\circ} 7$ de 2009. Código de Trabalho português. Diário da República, Lisboa, n. 30/2009, Série 1 de 12 fev. 2009. Disponível em: https://dre.pt/legislacaoconsolidada/-/lc/34546475/view. Acesso em: 17 set. 2020. 
PORTUGAL. Decreto-Lei $\mathrm{n}^{\circ}$ 47344. Código Civil. Diário do Governo, Lisboa, $\mathrm{n}^{\circ}$ 274/1966, Série 1 de 25 nov. 1966. Disponível em: https://dre.pt/web/guest/legislacao-consolidada/-

/lc/123928118/202009171824/73747564/diploma/indice. Acesso em: 17 set. 2020.

STF. HABEAS CORPUS: HC: 73351 SP, Relator: Min. ILMAR GALVÃO, DJ: 09/05/1996. JusBrasil, 1999. Disponível em: https://stf.jusbrasil.com.br/jurisprudencia/744091/habeas-corpus-hc-73351-sp. Acesso em: 28 out. 2020

TRT2. RECURSO ORDINARIO: RO 0000574-35.2013.5.02.0083. Rel. Jane Granzoto Torres da Silva. Data de Publicação: 14/06/2016. TRT2, 2016. Disponível em: $\quad$ https://pje.trt2.jus.br/consultaprocessual/detalheprocesso/00005743520135020083. Acesso em: 28 out. 2020.

RECURSO ORDINÁRIO: RO 1000891-55.2014.5.02.0382. Relator: Davi Furtado Meirelles. DEJT: 17/12/2014. TRT2, 2014. Disponível em: https://pje.trt2.jus.br/consultaprocessual/detalheprocesso/10008915520145020382. Acesso em: 28 out. 2020.

ROT 1000621-78.2019.5.02.0342. Relator: Flavio Villani Macedo. DEJT: $\overline{14 / 02 / 2020 .} \quad$ TRT2, 2020. Disponível em: https://pje.trt2.jus.br/consultaprocessual/detalheprocesso/10006217820195020342 Acesso em: 28 out. 2020.

TRT 15. RECURSO ORDINÁRIO, PROCEDIMENTO SUMARÍSSIMO : ROPS 0000656-55.2013.5.15.0002. Relatora: Patrícia Glugovskis Penna Martins. Data da Publicação 14/03/2014. TRT15, 2014. Disponível em: https://consulta.trt15.jus.br/consulta/owa/pProcesso.wProcesso?pTipoConsulta=P ROCESSOCNJ\&pidproc=2118800\&pdblink=. Acesso em: 28 out. 2020.

TRT-18. RO: 0001260-79.2011.5.18.0009, GRAVAÇÕES TELEFÔNICAS FEITAS PELO EMPREGADOR. LICITUDE. Relator: ALDON DO VALE ALVES TAGLIALEGNA, DJ: 07/02/2012, $1^{\text {a }}$ Turma.

TJSP. APELAÇ̃̃O : APL 4000515-21.2013.8.26.0451. Relator: Neves Amorim. DJ: 26/11/2013, Tribunal de Justiça de São Paulo, 2013. Disponível em: https://tjsp.jusbrasil.com.br/jurisprudencia/118726228/apelacao-apl40005152120138260451-sp-4000515-2120138260451. Acesso em: 28 out. 2020.

APELAÇÃO CÍVIL: AC 1024539-80.2018.8.26.0002. Relator: Gil Coelho. Data de publicação: 05/10/2020. Tribunal de Justiça de São Paulo, 2020. Disponível 
https://esaj.tjsp.jus.br/cjsg/getArquivo.do?conversationld=\&cdAcordao=14030349 \&cdForo=0\&uuid. Acesso em: 27 out. 2020.

TST. Acórdão do Processo $n^{\circ}$ RR-996100-34.2004.5.09.0015. Rel. Ministro Ives Gandra Martins Filho. Publicado em 18.02.2009. Jurisprudência TST, 2009. Disponível

em: https://jurisprudencia.tst.jus.br/\#63f1074a507ebd9b2db05362ba7598a. Acesso em: 27 out. 2020.

RECURSO DE REVISTA: RR 625-74.2011.5.09.0001. Relator: Ministro Emmanoel Pereira. DJ: 20/11/2012. Tribunal Superior do Trabalho, 2012. Disponível em: http://www.tst.jus.br/processos-do-tst. Acesso em: 28 out. 2020.

. AGRAVO DE INSTRUMENTO. RECURSO DE REVISTA : AIRR 88666.2012.5.04.0252. Relator: Vania Maria da Rocha Abensur, AD: 19/08/2015. JusBrasil. 2015.

Disponível

em: https://www.jusbrasil.com.br/processos/66699750/processo-n-00008866620125040252-do-trt-4?ref=goto. Acesso em: 28 out. 2020.

RECURSO DE REVISTA : RR 637-78.2014.5.04.0371, Relator Ministro Emmanoel Pereira, DEJT 04/03/2016. Tribunal Superior do Trabalho, 2016. Disponível em: http://www.tst.jus.br/processos-do-tst. Acesso em: 28 out. 2020.

AGRAVO DE INSTRUMENTO. RECURSO DE REVISTA : AIRR-236181.2015.5.02.0034. Relator: Ministro Vieira de Melo Filho. Assinado digitalmente em: 28/06/2016. Tribunal Superior do Trabalho, 2016. Disponível em: http://www.tst.jus.br/processos-do-tst. Acesso em: 28 out. 2020.

RECURSO DE REVISTA: RR-1793-64.2016.5.12.0030. Relator: Dora Maria da Costa, DJ: 23/10/2019 Jurisprudência TST, 2019. Disponível em: https://jurisprudencia.tst.jus.br/\#8f568cff22cb064a53fe98d6e910501c. Acesso em: 28 out. 2020.

RECURSO DE REVISTA: RR 7936420165120030, Relator: Dora Maria da Costa, DJ: 23/10/2019, $8^{a}$ Turma, Data de Publicação: DEJT 25/10/2019. Tribunal Superior do Trabalho, 2019. Disponível em: http://www.tst.jus.br/processos-do-tst. Acesso em: 28 out. 2020.

AGRAVO DE INSTRUMENTO. RECURSO DE REVISTA: AIRR-1106779.2018.5.18.0009, Relator Ministro Alberto Luiz Bresciani de Fontan Pereira, DEJT 25/10/2019. Superior Tribunal do Trabalho, 2019. Disponível em: http://www.tst.jus.br/processos-do-tst. Acesso em: 27 out. 2020. 
RECURSO DE REVISTA: RR1347-42.2014.5.12.0059, Relator Ministro Alexandre Luiz Ramos. DEJT: 26/06/2020. JusBrasil. 2020. Disponivel em: https://tst.jusbrasil.com.br/jurisprudencia/869026866/recurso-de-revista-rr13474220145120059?ref=juris-tabs. Acesso em: 28 out. 2020.

. AGRAVO DE INSTRUMENTO EM RECURSO DE REVISTA: AIRR $1000542-$ 40.2018.5.02.0373. Relatora: Ministra Delaíde Miranda Arantes. Assinado digitalmente em 18/10/2020. Tribunal Superior do Trabalho, 2020. Disponível em: http://www.tst.jus.br/processos-do-tst. Acesso em: 28 out. 2020.

THE UNITED STATES COURT OF APPEALS FOR THE FOURTH CIRCUIT. Appeal $\quad \mathrm{n}^{\circ}$ 12-1671. Disponível em: https://www.aclu.org/sites/default/files/field document/bland v. roberts appeal facebook amicus brief.pdf. Acesso em: 14 out. 2020.

UNIÃO EUROPEIA. Cour Européenne des Droits de L'Homme. AFFAIRE NIEMIETZ c. ALLEMAGNE (Requête $n^{\circ}$ ]13710/88). Strasbourg, 16 décembre 1992. Disponível em: http://hudoc.echr.coe.int/eng?i=001-62344 Acesso em: 15 set. 2020 .

Cour Européenne des Droits de L'Homme. AFFAIRE PECK c. ROYAUME-UNI (Requête no 44647/98). Strasbourg, 28 janvier 2003. Disponível em: http://hudoc.echr.coe.int/eng?i=001-65455. Acesso em: 15 set. 2020. 


\section{BIBLIOGRAFIA}

ABBAGNANO, Nicola. Dicionário de Filosofia. 6. ed. São Paulo: WMF Martins Fontes, 2012

AMARAL, Francisco. Direito Civil: introdução. 9. ed. São Paulo: Saraiva, 2017.

ASSIS, Rui. O Poder de Direcção do Empregador: Configuração geral e problemas actuais. Coimbra: Coimbra Editora, 2005.

BARROS, Alice Monteiro de. Curso de Direito do trabalho. 11. ed. São Paulo: LTr, 2017.

BAUMAN, Zygmunt. Vigilância líquida: diálogos com David Lyon. Rio de Janeiro: Zahar, 2013.

BELTRAN, Ari Possidonio. Direito do Trabalho: Limites do Poder e outras Questões da Atualidade. Revista do Advogado, v. 25, n. 82, p.10-21, 2005.

BELMONTE, Alexandre Agra. O Monitoramento da Correspondência Eletrônica nas Relações de Trabalho. 2. ed. São Paulo: LTr, 2014.

Direito do Trabalho: Limites do Poder e Outras Questões da Atualidade. Revista do Advogado, ano XXV, n. 82. São Paulo:AASP - Associação dos Advogados de São Paulo, 2005.

BITTAR, C. A. Os direitos da personalidade. 7. ed. Rio de Janeiro: Forense Universitária, 2006.

BOBBIO, Norberto. Teoria Geral da Política: a Filosofia Política e as Lições dos Clássicos. Rio de Janeiro: Elsevier, 2000.

A Era dos Direitos. Rio de Janeiro: LTC, 2020.

BOTIJA, Eugenio Perez. Curso de Derecho del Trabajo. Madrid: Editorial Tecnos, 1948.

CAMPOS, Diogo Leite de. Lições de Direitos da Personalidade. 2. ed. Coimbra: Separata do vol. LXVI (1990) do Boletim da Faculdade de Direito da Universidade de Coimbra, 1995. 
CATHARINO, J. M. Compêndio de Direito do Trabalho. 3. ed. São Paulo: Saraiva, 1982. v. I.

CHINELLATO, Silmara Juny (coord.). Código Civil Interpretado - artigo por artigo, parágrafo por parágrafo. 13. ed. Barueri: Manole, 2020.

COOLEY, Thomas M. A Treatise on the Law of Torts or the Wrongs Which Arise Independent of Contract. Chicago: Callaghan and Company, 1879.

Comitê Gestor da Internet no Brasil. Pesquisa sobre o uso das tecnologias de informação e comunicação nos domicílios brasileiros. São Paulo: CGI, 2019. p. 122. Disponível em: https://www.cgi.br/media/docs/publicacoes/2/12225320191028tic dom 2018 livro eletronico.pdf'. Acesso: 03 out. 2020.

COMPARATO, Fábio Konder. A Afirmação Histórica dos Direitos Humanos. 11.ed. São Paulo: Saraiva, 2017.

CORDEIRO, António Menezes. Tratado de Direito Civil IV, Parte Geral: Pessoas. 4 ed. Coimbra: Almedina. 2016.

CORNU, Gérard. Vocabulaire Juridique. 12. ed. Paris: Presses Universitaires de France, 2018

COSTA JR, Paulo Jose da. O Direito de estar só: Tutela Penal da Intimidade. São Paulo: RT, 1970.

CUPIS, Adriano de. Os Direitos da Personalidade. Lisboa: Livraria Morais Editora, 1961.

DAL-RÉ, Fernando Valdés. Prólogo. In: ROMÁN, María Dolores. Poder de dirección y contrato de trabajo. Valladolid: Ediciones Grapheus, 1992.

DELGADO, Maurício Godinho. O Poder Empregatício. São Paulo: LTr, 1996.

Curso de Direito do Trabalho: obra revista e atualizada conforme a lei da

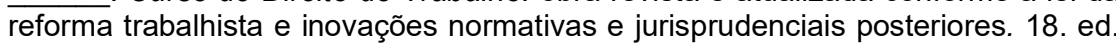
São Paulo: LTr, 2019. 
DURAND, P.; JAUSSARD, R. Traité de Droit du Travail. Paris: Libraire Salloz, 1947. V. I.

FACEBOOK. Disponível em: https://www.facebook.com/. Acesso em: 23 set. 2020.

FERNANDES, Milton. Os direitos da Personalidade. In: BARROS Hamilton de Moraes et al. Estudos Jurídicos em Homenagem ao Professor Caio Mário da Silva Pereira. Rio de Janeiro: Ed. Forense, 1984.

FILHO, Evaristo de Moraes; MORAES, Antonio Carlos Flores de. Introdução ao Direito do Trabalho. 11. ed. São Paulo: LTr, 2014.

FOUCAULT, Michel. Microfísica do Poder. 10. ed. São Paulo: Paz e Terra, 2019.

FRANÇA, R. Limongi. Direitos da Personalidade - Coordenadas Fundamentais. In: MENDES, Gilmar Ferreira; STOCO, Rui (org.). Doutrinas Essenciais - Direito Civil Parte Geral: Pessoas e Domicílios - Aspectos Gerais, Pessoas Naturais, Pessoas Jurídicas e Domicílio. São Paulo: RT, 2011. v. 3, cap. 35.

Direitos Privados da Personalidade. In: STOCO, Rui, Doutrinas Essenciais - Dano Moral - Teoria do Dano Moral e Direitos da Personalidade. São Paulo: RT, 2015. v.1.

GOMES, Luiz Roldão de Freitas. Noção de Pessoa no Direito brasileiro. In: MENDES, Gilmar Ferreira; STOCO, Rui (org.). Doutrinas Essenciais - Direito Civil -Parte Geral: Pessoas e Domicílio. São Paulo: Revista dos Tribunais, 2011. v. III, p. $55-81$.

GUIDINI, Mario. Diritto del Lavoro. Parte Generale - Diritto Sindacale - Contratto individuale di lavoro - Controversie del Lavoro. Padova: CEDAM, 1976.

JABUR, Gilberto Haddad. Liberdade de Pensamento e Direito à Vida Privada: Conflitos entre Direitos da Personalidade. São Paulo: Editora Revista dos Tribunais, 2000.

JAVILLIER, Jean-Claude. Droit du Travail. Paris : Librairie Generale de Droit et de Jurisprudence, 1978.

LEITÃO, Luís Manuel Teles de Menezes. Direito do Trabalho. 3. ed. Coimbra: Almedina, 2012. 
LENER, Angelo. Potere - Diritto Privato. In: CALASSO, Francesco. Enciclopedia del Diritto: XXXIV. Milano: Giuffré Editore, 1995, p. 610-642

LEWICK, Bruno. A Privacidade da Pessoa Humana no Ambiente de Trabalho. Rio de Janeiro: Renovar, 2003.

LIMBERGER, Têmis. O Direito à Intimidade na Era da Informática: a Necessidade de Proteção soa Dados Pessoais. Porto Alegre: Livraria do Advogado Editora, 2007.

MAGANO, Octavio Bueno. Do Poder Diretivo na Empresa. São Paulo: Editora Saraiva, 1982.

MAIOR, Jorge Luiz Souto. Curso de Direito do Trabalho: a Relação de Emprego. São Paulo: LTr, 2008. v. II.

MAIOR, Jorge Luiz Souto. Do Direito à Desconexão do Trabalho. Revista do Tribunal Regional do Trabalho da $15^{a}$ Região, v. 23, p. 296- 313, 2003.

MALLET, E. Apontamentos sobre o direito à intimidade no âmbito do contrato de trabalho. Revista da Faculdade de Direito da Universidade de São Paulo, v. 104, p. 199-226, 2009

MARANHÃO, Délio. Direito do Trabalho. 6. ed. Rio de Janeiro: Editora da Fundação Getulio Vargas, 1978.

MARTINEZ, Pedro Romano. Direito do Trabalho. 8. ed. Coimbra: Almedina, 2017.

MARTINS, Sergio Pinto. Direito do Trabalho. 31. ed. São Paulo: Editora Atlas, 2015.

MATTIA, Fábio Maria de. Direitos da personalidade: aspectos gerais. Revista de informação legislativa, v. 14, n. 56, p. 247-266, out./dez. 1977.

MESQUITA, Luiz José de. Direito Disciplinar do Trabalho. 2. ed. São Paulo: LTr, 1991.

MIRANDA, Pontes de. Tratado de Direito Privado. Parte Especial. Direito de Personalidade. Direito de Família: Direito matrimonial (Existência e Validade do Casamento). 3. ed. Rio de Janeiro: Editor Borsoi, 1971. v. 7. 
MONTESQUIEU, Charles de Secondat, Baron de. Do espírito das leis. São Paulo: Martin Claret, 2014.

MORATO, Antonio Carlos. Quadro Geral dos Direitos da Personalidade. Revista da Faculdade de Direito da Universidade de São Paulo. v. 106/107, p. 131-132, dez./jan. 2011/2012.

NASCIMENTO, Amauri Mascaro. NASCIMENTO, Sônia Mascaro. Curso de Direito do Trabalho: História e Teoria Geral do Direito do Trabalho: Relações individuais e coletivas do Trabalho. 29. ed. São Paulo: Saraiva, 2014.

NASCIMENTO, Amauri Mascaro; NASCIMENTO, Sônia Mascaro. Iniciação ao Direito do Trabalho. 40. ed. São Paulo: LTr, 2015.

NERY, Rosa Maria de Andrade.; NERY JUNIOR, Nelson. Instituições de Direito Civil: Teoria Geral do Direito Privado. São Paulo: Editora Revista dos Tribunais, 2014. v. I. t. I.

OLEA, Manuel Alonso; BAAMONDE, Maria Emilia Casa. Derecho del Trabajo. 17. ed. Madrid: Civitas Ediciones, 1999.

OLIVEIRA, Paulo Eduardo Vieira de. A privacidade da Pessoa Humana no Ambiente de Trabalho. Revista da Faculdade de Direito da Universidade de São Paulo. v. 100, p. 147-167, jan./dez. 2005.

OLIVEIRA, Paulo Eduardo Vieira de. Campo de Aplicação do Direito do Trabalho Sujeitos: Empregador e Empregado. In: MAIOR, Jorge Luiz Souto; CORREIRA, Marcus Orione Gonçalves (org.). Curso de Direito do Trabalho - Direito Individual do Trabalho. São Paulo: LTr, 2008. v. 2.

ORWELL, George. 1984. São Paulo: Companhia das Letras, 2009.

PAVELSKI, Ana Paula. Os Direitos de Personalidade do Empregado: em face do exercício abusivo do poder diretivo do empregador. Curitiba: Jaruá, 2009.

PEREIRA, Caio Mario da Silva. Instituições de Direito Civil - Introdução ao Direito Civil. Teoria Geral do Direito Civil. 9. ed. Rio de Janeiro: Forense, 1985. v. 1. 
RAMALHO, Maria do Rosário Palma. Tratado de Direito do Trabalho: Situações Laborais Individuais. 6. ed. Coimbra: Almedina, 2016. v. 2.

REALE, Miguel. Lições Preliminares de Direito. São Paulo: Saraiva, 2002.

RODOTÀ, Stefano. A Vida na Sociedade da Vigilância - a Privacidade hoje. Rio de Janeiro: Renovar, 2008.

RIGAUX, F. La liberté de la vie privée. Revue internationale de droit comparé., v. 43, n. 3, jul./set. 1991.

ROMÁN, María Dolores. Poder de dirección y contrato de trabajo. Valladolid: Ediciones Grapheus, 1992.

ROMITA, Arion Sayão. O poder disciplinar do empregador. Rio de Janeiro: Livraria Freitas Bastos, 1983.

ROMITA, Arion Sayão. Os Poderes do Empregador e os Deveres do Empregado na Relação de Emprego, segundo Délio Maranhão, Revista do Tribunal Superior do Trabalho, São Paulo, v. 81, n. 3, p. 37-52, jul./set. 2015.

RUSSOMANO, Mozart Victor. Curso de Direito do Trabalho. 9. ed. Curitiba: Juruá, 2016.

SANSEVERINO, Riva. Curso de Direito do Trabalho. Trad. Orlando Gottschalk. São Paulo: LTr, 1976.

SANTOS, Enoque Ribeiro dos. Limites ao poder disciplinar do empregador - a tese do poder disciplinar compartilhado. LTr: Revista legislação do trabalho, São Paulo, v. 72 , n. 5 , p. $545-556,2008$.

SARLET, Ingo Wolfgang. Dignidade (da Pessoa) Humana e Direitos Fundamentais na Constituição Federal de 1988. 10. ed. Porto Alegre: Livraria do Advogado, 2019.

SILVA, Orosimbo Nonato da. Personalidade, In: SANTOS, J. M. De Carvalho. Repertório Enciclopédico do Direito Brasileiro. Rio de Janeiro: Borsoi, 1947, v. XXXVII.

SILVA, J. A. da. Comentário Contextual à Constituição. 9.ed. São Paulo: Malheiros Editores, 2014. 
SOUSA, Rabindranath Valentino Aleixo Capelo de. O Direito Geral de Personalidade. Coimbra: Coimbra Editora, 1995.

STRAHILEVITZ, Lior. A Social Networks Theory of Privacy. University of Chicago Law Review, v. 72, n. 3, p. 919-988, 2005.

SÜSSEKIND, Arnaldo. Curso de Direito do Trabalho. 3. ed. Rio de Janeiro: Renovar, 2010.

SZANIAWSKI, Elimar. Direitos da Personalidade e sua Tutela. São Paulo: RT, 1993.

TEPEDINO, Gustavo; BARBOZA, Heloisa Helena; DE MORAES, Celina Bodin. Código Civil interpretado conforme a Constituição da República. 3. ed. Rio de Janeiro: Renovar, 2014. v. I.

TOBEÑAS, José Castan. Los Derechos de la Personalidad. Madrid: Instituto Editorial Reus, 1952.

TOMASEVICIUS FILHO, E. Em direção a um novo 1984? A tutela da vida privada entre a invasão e privacidade e a privacidade renunciada. Revista da Faculdade de Direito da Universidade de São Paulo, v. 109, p. 129-169, dez. 2014.

TORRENTE, Andrea; SCHLESINGER, Piero. Manuale di Diritto Privato. 20. ed. Milão: Giuffrè Editore, 2017.

TRABUCCHI, Alberto. Istituzioni di Diritto Civile. 18. ed. Padova: CEDAM, 1971

VASCONCELOS, Pedro Pais de. Direito de Personalidade. Coimbra: Almedina, 2006.

VILE, John R. Essential Supreme Court Decisions: summaries of leading cases in U.S constitutional law. 16. ed. Maryland: Rowman \& Littlefield, 2014.

WARREN, Samuel D.; BRANDEIS, Louis D. The right to Privacy. Harvard Law Review., v. IV, n. 5, Boston, 1890.

WEBER, Max. Ensaios de Sociologia. 5. ed. Rio de Janeiro: LTC, 1982. 
ZARSKY, Tal. Law and Online Social Networks: Mapping the Challenges and Promises of User-Generated Information Flows. Fordham Intellectual Property, Media \& Entertainment Law Journal, v. 18, n. 3, 2008. p. 31.

ZANFARINO, Antonio. a) Filosofia del Diritto, I Potere (in generale). In: CALASSO, Francesco. Enciclopedia del Diritto. Milano: Giuffrè Editore. vol. XXXIV. p. 599-609. 